\title{
Platelet monoamine oxidase activity in megaloblastic anaemia
}

\author{
VIVETTE GLOVER, * M SANDLER, * A HUGHES, $\dagger$ AND AV HOFFBRAND $\dagger$ \\ From the *Bernhard Baron Memorial Research Laboratories and Institute of Obstetrics and Gynaecology, \\ Queen Charlotte's Maternity Hospital, London W6 OXG and the †Department of Haematology, Royal \\ Free Hospital, London NW3 2QG, UK
}

SUMmaRY Platelet monoamine oxidase activity has been measured in 17 patients with megaloblastic anaemia due to either vitamin $\mathrm{B}_{12}$ or folate deficiency, and in 20 healthy subjects. There was a highly significant increase in patients compared with controls. In two patients, platelet activity decreased following successful treatment. A significant correlation between platelet activity and the severity of bone marrow megaloblastic change, assessed by the deoxyuridine suppression test and bone marrow morphology, was also observed. If the change in activity also occurs in the nervous system, this may contribute to the mental disturbance associated with vitamin $B_{12}$ or folate deficiency.

The widespread mitochondrial enzyme monoamine oxidase (MAO) metabolises a broad range of biologically active monoamines thought to be important for the normal functioning of the brain. The enzyme exists in two forms with different substrate specificity: MAO A predominantly oxidises 5-hydroxytryptamine and noradrenaline, whereas MAO B acts on phenylethylamine and tele-methylhistamine. Dopamine can be a substrate for both forms. As the human brain enzyme is inaccessible, platelet activity has been extensively studied as an indicator of possible enzyme involvement in certain diseases of the central nervous system, although the human platelet possesses only the $\mathbf{B}$ form. A decrease in platelet activity has been found in schizophrenia, ${ }^{1}$ an increase in depression, ${ }^{2}$ and transient changes in migraine $^{3}$ and alcoholism. ${ }^{4}$ Here we extend a preliminary abstract of Latt and her colleagues, ${ }^{5}$ suggesting that platelet MAO activity is raised in megaloblastic anaemia.

\section{Methods}

Seventeen patients ( 9 male, 8 female) with megaloblastic anaemia due to vitamin $\mathbf{B}_{12}$ or folate deficiency, and 20 normal blood donors (10 male, 10 female), were studied. In all 17 patients, the mean corpuscular volume was greater than $100 \mathrm{fl}$ (range 101-128 fl). The haemoglobin levels ranged from $5 \cdot 7$ to $12.0 \mathrm{~g} / \mathrm{dl}$ in the nine males and from 4.6 to $10 \cdot 8$ $\mathrm{g} / \mathrm{dl}$ in the eight females. Megaloblastic change was

Received for publication 26 February 1980 determined by morphological examination of May-Grünwald-Giemsa stained marrow smears, and the severity was graded + to $+++(+$ mild changes; +++ florid changes). Iron stores were present in all cases. Deoxyuridine (dU) suppression of tritiated thymidine uptake tests were carried out on bone marrow samples from nine patients, as described by Killman ${ }^{6}$ and Metz et al. ${ }^{7}$ Serum vitamin $\mathrm{B}_{12}$ and folate concentrations were measured by microbiological assay using Euglena gracilis and Lactobacillus casei, respectively.

Platelets were prepared in EDTA as described previously. ${ }^{3}$ MAO was assayed using ${ }^{14} \mathrm{C}$-phenylethylamine (PEA), as described previously, ${ }^{3}$ except that the reaction was terminated with $2 \mathrm{M}$ citric acid $(0.1 \mathrm{ml})$ and the product was extracted into toluene (3 ml). Protein was assayed by Lowry's method, ${ }^{8}$ and all measurements were carried out blind and in duplicate. Enzyme activity is expressed in units consisting of nmoles PEA oxidised/mg protein per hour.

\section{Results}

The mean \pm SD platelet MAO activity of the 17 patients ( $32 \pm 1.2$ units) was significantly raised compared with that of the control group $(15 \pm 3 \cdot 8$ units), $\mathrm{P}<0.001$ (two-tailed Student's $t$ test). Ten of the 17 patients with megaloblastic anaemia had levels above the upper limit ( 26 units) of the normal range (Figure). Two patients were retested after two months of vitamin $B_{12}$ therapy, and in each case platelet activity had fallen to normal, from 57 to 22 


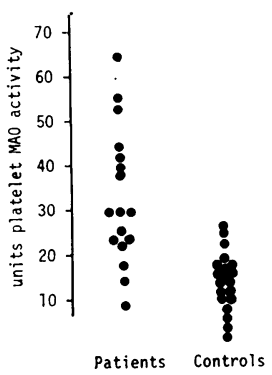

Platelet monoamine oxidase (MAO) activity in patieots with megaloblastic anaemia and in controls.

units in one and from 22 to 9 units in the other. The Table compares platelet MAO activity with other measurements in the same patient. There was significant correlation with both the degree of abnormality of the dU suppression test $(P<0.025)$ and marrow morphology $(P<0.05)$, both by onetailed Student's $t$ tests. There was no relationship between platelet MAO activity and initial haemoglobin concentration or platelet count. There was no difference between the patients with anaemia due to vitamin $B_{12}$ deficiency or folate deficiency, nor in the patients with vitamin $B_{12}$ or folate deficiency considered separately was there a correlation of platelet MAO activity with serum vitamin $\mathbf{B}_{12}$ or folate level (Table).

Platelet MAO activity compared with other indices of megaloblastic anaemia

\begin{tabular}{|c|c|c|c|c|}
\hline $\begin{array}{l}\text { Platelet } M A O \\
\text { activity } \\
\text { (units) }\end{array}$ & $d U$ suppression & $\begin{array}{l}\text { Marrow } \\
\text { morphology }\end{array}$ & $\begin{array}{l}\text { Vitamin } B_{12} \\
\text { (normal } \\
160-925 \\
p g / m l)\end{array}$ & $\begin{array}{l}\text { Serum } \\
\text { folate } \\
\text { (normal } \\
3-21 \\
\text { ng/ml) }\end{array}$ \\
\hline $\begin{array}{r}64 \\
57 \\
56 \\
43 \\
41 \\
40 \\
39 \\
30 \\
30 \\
30 \\
24 \\
22 \\
22 \\
21 \\
16 \\
14 \\
9\end{array}$ & $\begin{array}{l}- \\
- \\
\overline{30} \\
34 \\
15 \\
28 \\
16 \\
- \\
\overline{19} \\
21 \\
\overline{15} \\
10 \\
\bar{P}<0.025\end{array}$ & $\begin{array}{c}++ \\
++ \\
+ \\
++ \\
++ \\
+ \\
++ \\
++ \\
++ \\
+ \\
+ \\
++ \\
++ \\
+ \\
+ \\
+ \\
+ \\
+ \\
\text { P } 0.05\end{array}$ & $\begin{array}{r}310 \\
0 \\
10 \\
0 \\
20 \\
20 \\
170 \\
30 \\
110 \\
220 \\
80 \\
20 \\
20 \\
30 \\
120 \\
60 \\
210 \\
\text { NS }\end{array}$ & \begin{tabular}{r|}
$1 \cdot 0$ \\
$5 \cdot 8$ \\
28 \\
$17 \cdot 6$ \\
$4 \cdot 0$ \\
$26 \cdot 8$ \\
$0 \cdot 8$ \\
$6 \cdot 0$ \\
$2 \cdot 1$ \\
$3 \cdot 0$ \\
$13 \cdot 0$ \\
$7 \cdot 0$ \\
$12 \cdot 0$ \\
$12 \cdot 8$ \\
0.6 \\
$7 \cdot 2$ \\
2.8 \\
NS
\end{tabular} \\
\hline
\end{tabular}

\section{Discussion}

Platelet MAO activity is to some extent under genetic control, as shown by twin studies. ${ }^{9}$ However, other factors, including adrenaline injection, ${ }^{10}$ exercise, ${ }^{11}$ glucose ingestion, ${ }^{12}$ and unknown small molecule endogenous activators ${ }^{13}$ or inhibitors, ${ }^{14}$ are able to alter platelet MAO activity.

Our results show that platelet MAO activity can be greatly increased in megaloblastic anaemia, and that the increase is related to the severity of megaloblastic change as assessed by bone marrow morphology or dU suppression test. Serum levels of either vitamin $B_{12}$ or folate are not reliable guides to the degree of megaloblastic changes as very low concentrations of either vitamin may be associated with either severe or mild changes. There is an overlap in activity between the patient and control group, especially when there is a mild degree of megaloblastic change and the measurement of platelet MAO activity cannot replace marrow aspiration in the diagnosis of megaloblastic anaemia. However, the ease of measuring platelet MAO activity and its correlation with the severity of marrow megaloblastic change suggest that, in certain circumstances, especially when marrow aspiration is impracticable, it may be a useful diagnostic aid. Studies of activity in other haematological conditions, in which there may be macrocytosis without megaloblastic change, for example, in some alcoholics, liver disease, and myxoedema, are needed before a firm opinion can be given of the specificity of the raised platelet MAO noted here to megaloblastic anaemia due to folate or vitamin $\mathbf{B}_{12}$ deficiency.

One explanation of the increased activity is that it is associated with an altered population of platelets in megaloblastic anaemia. In autoimmune thrombocytopenic purpura, in which there is a young circulating platelet population, Friedhoff et al. ${ }^{15}$ have shown that the platelet MAO specific activity is much reduced. Megaloblastic anaemia is characterised by an increase in serum lactate dehydrogenase activity, stemming from both intramedullary lysis of cells and from the fact that megaloblasts have a higher than normal activity of the enzyme. This may reflect an increase in cell cycle time. As thrombopoiesis is affected in a similar manner to erythropoiesis, it is reasonable to suppose that an increase in platelet MAO content may similarly occur through prolonged maturation associated with increased RNA and protein synthesis.

However, the observation of Murphy et al. ${ }^{16}$ that substantial differences in platelet MAO activity are present between some individuals in all platelet density fractions shows that individual variation in expression of the enzyme as well as differences in platelet subpopulations are important in determining platelet MAO levels. It is possible that the metabolic changes induced by vitamin $B_{12}$ and folate deficiency, which are most marked in haemopoietic 
cells, include a generalised increase in MAO activity throughout the body. Psychiatric symptoms can occur in vitamin $B_{12}$ and folate deficiency, and in one survey ${ }^{17}$ of 101 patients presenting with a depressive illness, $24 \%$ were found to have subnormal folate levels. A recent study has linked amine metabolism with folate deficiency 18 by showing that folatedeficient rats have a decrease in brain 5-hydroxytryptamine concentration. A marked increase of MAO activity in the brain might reduce the concentration of noradrenaline or 5-hydroxytryptamine in the synaptic cleft and thus, in accordance with the somewhat simplistic amine hypothesis, ${ }^{19}$ contribute to the generation of depressive symptoms.

The mechanisms controlling platelet MAO activity are obviously complex. It is now important to determine whether the changes described here are merely secondary to maturational deficit or truly reflect alterations in central MAO metabolism.

\section{References}

1 Wyatt RJ, Potkin SG, Murphy DL. Platelet monoamine oxidase activity in schizophrenia: a review of the data. Am J Psychiat 1979;136:377-85.

2 Nies A, Robinson DS, Harris LS, Lamborn KR. Comparison of monoamine oxidase substrate activities in twins, schizophrenics, depressives and controls. In: Usdin E, ed. Neuropsychopharmacology of Monoamines and their Regulatory Enzymes. New York: Raven Press, 1974; 59-70.

${ }^{3}$ Glover V, Sandler M, Grant E, Rose FC, Orton D, Wilkinson M, Stevens D. Transitory decrease in platelet monoamine oxidase activity during migraine attacks. Lancet $1977 ; 1: 391-3$.

4 Wiberg A, Gottfries C-G, Oreland L. Low platelet monoamine oxidase activity in human alcoholics. Med Biol 1977;55:181-6.

${ }^{5}$ Latt N, Rippey JJ, Stacey RS. Monoamine oxidase activity of platelets. Br J Pharmac 1968;32:427P.

- Killman S-A. Effect of deoxyuridine or incorporation of tritiated thymidine: difference between normoblasts and megaloblasts. Acta Med Scand 1964;175:489.

${ }^{7}$ Metz J, Kelly A, Swett VC, Waxman S, Herbert V.
Deranged DNA synthesis in bone marrow from $B_{12}$ deficient humans. Br J Haem 1968;14:575.

${ }^{8}$ Lowry OH, Rosebrough MJ, Farr AL, Randall RJ. Protein measurement with the Folin phenol reagent. J Biol Chem 1951;193:265-75.

- Nies A, Robinson DS, Lamborn KR, Lamport RP, Burlington VE. Genetic control of platelet and plasma monoamine oxidase activity. Arch Gen Psychiat 1973;28: $8 \quad 34-8$.

${ }^{10}$ Gentil V, Greenwood MH, Lader MH. The effect of adrenaline on human platelet MAO activity. Psychopharmacologia $1975 ; 44: 187-90$.

11 Gawel M, Glover V, Park D, Rose FC, Sandler M. The effect of exercise upon platelet MAO B activity. Clin Sci Mol Med 1977;52:32P.

12 Demisch L, Demisch K, Seiler N. Factors altering platelet monoamine oxidase. The influence of oral glucose intake. Metabolism 1979;28:144-50.

$13 \mathrm{Yu}$ PH, Boulton AA. Activation of platelet monoamine oxidase by plasma in the human. Life Sci 1979;25:31-6.

14 Sandler M, Glover V, Elsworth J, Lewinsohn R, Reveley M. Monoamine oxidase inhibition: some clinical dimensions. In: Sandler M, ed. Enzyme Inhibitors as Drugs. London: Macmillan, 1980;173-82.

15 Friedhoff AJ, Miller JC, Karpatkin S. Heterogeneity of human platelets. VII. Platelet monoamine oxidase activity in normals and patients with autoimmune thrombocytopenic purpura and reactive thrombocytosis; its relationship to platelet protein density. Blood $1978 ; 51: 317-23$.

16 Murphy DL, Costa JL, Shafer B, Carash L. Monoamine oxidase activity in different density gradient fractions of human platelets. Psychopharmacology 1978;59:193-7.

17 Reynolds EH, Preece JM, Bailey J, Coppen A. Folate deficiency in depressive illness. Br J Psychiat 1970;117: 287-92.

${ }^{18}$ Botez MI, Young SH, Bachevalier J, Gauthier S. Folate deficiency and decreased brain 5-hydroxytryptamine synthesis in man and rat. Nature 1979;278:182-3.

19 Schildkraut JJ. The catecholamine hypothesis of affective disorders: a review of supporting evidence. Am J Psychiat 1965;122:509-22.

Requests for reprints to: Professor M Sandler, Bernhard Baron Memorial Research Laboratories and Institute of Obstetrics and Gynaecology, Queen Charlotte's Maternity Hospital, London W6 0XG, UK. 